\title{
TV/Series
}

3 | 2013

Écho et reprise dans les séries télévisées (I) : Reprise

et intermédialité

\section{Treme: New Orleans Remix}

\section{Ariane Hudelet}

\section{(2) OpenEdition \\ Journals}

Electronic version

URL: http://journals.openedition.org/tvseries/722

DOI: $10.4000 /$ tvseries.722

ISSN: 2266-0909

Publisher

GRIC - Groupe de recherche Identités et Cultures

\section{Electronic reference}

Ariane Hudelet, «Treme: New Orleans Remix », TV/Series [Online], 3 | 2013, Online since 15 September 2013, connection on 19 April 2019. URL : http://journals.openedition.org/tvseries/722 ; DOI : 10.4000/ tvseries.722

\section{(a) $\oplus \Theta \Theta$}

TV/Series est mis à disposition selon les termes de la licence Creative Commons Attribution - Pas d'Utilisation Commerciale - Pas de Modification 4.0 International. 
Treme: New Orleans Remix

Ariane HUDELET

The three seasons of Treme broadcast so far on HBO show how life, in all its forms (economic, social, cultural), resumed in New Orleans after Hurricane Katrina. The multitrack dimension of the show (we see bits and pieces of the existence of common people, without a rigid narrative structure) falls into one form of the serial narrative, which tends to erase the notions of beginning and ending and gives the impression of a flow in which we get caught for the duration of each episode. The passages from one narrative arc to another occur very fluidly, evoking a musical construction. Indeed, by using as a main structure the different musical performances which punctuate the series, Treme is above all a recreation of the rhythm and beat of a city: music accompanies the important moments of the lives of these characters, and the major stages of the plot and of character development seem to follow the typical jazz structure - recurring phrases submitted to variations and improvisations. The combination of historical facts and fiction in this musical structure also allows Treme to take up highly political issues: it reflects the specificity of a city that refuses to give in, and strongly defends its culture. This article focuses on the way these original narrative and aesthetic choices manage to echo a political questioning of the nature of the trauma that hit New Orleans in 2005. Far from being a natural, inevitable disaster like the hurricane itself, the flooding which ensued was, in Creighton Bernette's terms (the character performed by John Goodman) "a man-made catastrophe, a federal fuck up of epic proportions, and decades in the making." Treme's fictional enterprise could thus be seen as an attempt to reorchestrate this recent history and its human consequences, unlike stereotypical media or political representations.

fter The Wire (HBO, 2002-2008) became such a critical success, David Simon's new series was eagerly expected. Following the 1 miniseries Generation Kill (HBO, 2008), the showrunner changed horizons with Treme (HBO, 2010-), the reception of which has so far been mixed. Those who expected to see another Wire were of course disappointed. Treme is no sequel, remake or recycling of The Wire. The depiction of post-Katrina New Orleans through several individuals embodying the lively culture of the city does not follow the same encompassing, multi-faceted ambition that the five seasons of The Wire had. For some, Treme is too realistic and verges on the touristic approach; for others, it presents a problematic, idealized vision of the communities it depicts. For some, there is not enough narrative drive; for others - like me - it is on the contrary the enthralling depiction of a unique culture, and a landmark in the series form. Creators David Simon and Eric Overmyer have repeatedly stressed in interviews that Treme is "a show about culture", and about the specific culture of New Orleans, which is more participatory than spectatorial ${ }^{1}$. What I will try to show in this paper is that, in order to appreciate Treme, one has to adopt the relationship to culture that the show represents. What dominates this culture, next to food and mystical traditions, is the music. I will consider how the show, more

${ }^{1}$ See for instance "The Art of Treme" conference on DVD4, Season 2. 
than remaking or recycling, actually remixes reality in a musical way to create a unique type of serial and participatory spectacle. In TV series, usual tools to sustain the audience's interest include cliffhangers, plot twists, embedded narration, time manipulations, etc. There are no such devices in Treme, which could be considered to use music as main structure, as much as, or even more than, narrative elements. Just as jazz relies on improvisations and variations based on an initial motif, the series offers narrative lines that could be seen as melodic, resonating with each other to build a cohesive and expressive work. After studying how music is a vital part of the series and influences its aesthetics, I will see how these aesthetic choices necessarily bear on the political and ideological message of the series, and thus I will try to respond to some of the criticisms that have been addressed to the show. Instead of focusing exclusively on the recycling of real places, facts or people that Treme indeed strongly relies on, choosing music, and jazz in particular, as an analytical tool to understand the series allows us to focus on another dimension, which encourages audience participation and political engagement.

\section{Remixing the New Orleans Musical Scene}

While the show portrays all sorts of activities and the way people try to rebuild and preserve what New Orleans is about, music stands out. As in most areas covered by the show, the limit between fiction and reality is often blurred, since some of the musicians are fictional characters (Antoine Batiste the trombone player who struggles for some gigs, played by Wendell Pierce, or Sonny and Annie who are street buskers at the beginning of Season 1) while real musicians from the New Orleans scene such as Kermit Ruffins, John Boutté or internationally famous Dr. John or hip hop star Juvenile appear as well, performing their own roles.

Music is included in all possible ways and forms, above all in live performances, which reflect the inscription of music within the city, from nominally acknowledged venues (Tipitinas, the Spotted Cat, DBA...), to street performances (street busking, second-lines, Mardi Gras Indians parades, etc.), from studio recordings to radio broadcasting, or to background music played on the radio, for instance in the kitchens of the restaurants where chefs are working.

Although the focus remains primarily on jazz music (and on the variety of music corresponding to the term, from traditional to modern), many other genres and forms are featured as well, from rock and roll to zydeco, and in Season 2, hip hop in the form of bounce, not forgetting Cajun music, soul or rhythm and blues. What characterizes most types of music represented on screen is the fact that they're all recorded live on the set (and on that scale, it had never been done before), as well as the degree of involvement required of the audience, 
and the association between culture and resilience after the trauma. Music is so embedded in the narrative that it is very difficult to "track" the different musical parts, as opposed to other recent musical shows like Glee or Smash for instance. In an interview for Billboard, David Simon explains:

What music has achieved is part of the story. But it's not a lot of performance footage compared to the average rock'n'roll movie. We were really conscious of the fact that we have to have a point of view in the room. What we don't want is that moment from [the 1956 film] The Girl Can't Help It, where it's "Hey, Fats, how about playing one for the kids?" And he plays "Ain't That a Shame”. Dissolve in applause, and then dialogue. If at any point the story stops for a piece of music, then we screwed up ${ }^{2}$.

It would indeed be hard to distinguish musical and non-musical moments in Treme, since most dimensions of the show (narrative construction, rhythm, mise-en-scène, editing) resort to musical figures and tropes, as we shall see.

\section{Jazz or the Interweaving of Individual Melody and Collective Harmony}

The story indeed never stops for music. On the contrary, the form chosen by the series adopts some features of the music it showcases - to use Tim Woodall's terms in the Independent, music is "the end, not the means 3 ".

The first feature of jazz music that the series adopts in its own form is the way the melodic lines of the different instruments combine and flourish within a collective harmony. Like jazz, the series relies on individual performances that combine and resonate which each other to produce meaning. There is no main character in the show; all of them occupy more or less a similar status within the series, and what matters is not so much the individual progress of each character or group of characters, but the way the series edits these bits and pieces together and inserts them within the overarching beat of the city itself and its slow reconstruction.

This harmonious, or sometimes dissonant, or swinging interaction between different musical lines or individual trajectories is represented metaphorically as early as the opening title sequence, in the way the letters of the credits seem to expand, and combine with the other movements within the shots in an effect that we can call

${ }^{2}$ Larry Blumenfeld, "Rhythm and Blue. David Simon's New HBO series Treme Moves to a Crescent City beat", Billboard, 10 April 2010.

3 "Music isn't used as aural wallpaper or scene setting; it is the end not the means". Tim Woodall, "Treme: The most musical TV series ever?", The Independent blog, 25 October 2011. http://blogs.independent.co.uk/2011/10/25/treme-the-most-musical-tv-series-ever/ Consulted December 13, 2012. 
polyrhythmic. The first credits, for instance, appear against shots of walls covered with mold (see Plates 1 and 2). All the shots play with complementary, simultaneous movements: a quick zoom out on the mold motif, quickly followed by a slow zoom in, sometimes combined with a pan, while the letters of the credits themselves slide into the screen, and then slowly expand into the frame, endowing each shot with a complementary rhythm, in the manner of what is called polyrhythm, a staple of jazz music (the simultaneous use of two or more conflicting rhythms, that do not appear to derive from one another, or to be manifestations of the same meter 4 ). The way individual lives combine in the series seems to me to correspond to this brief moment in the credits in which the conjugation of different movements creates harmony and dynamics.

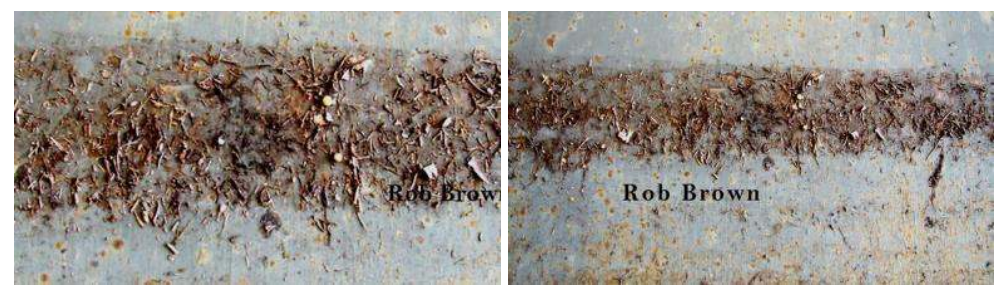

Plates 1 and 2.

It is the combination of these individual lives which produces meaning or effect, as the opening sequence of the pilot episode shows. It starts with a series of extreme close ups, details of bodies of different skin colors, genders and ages, instruments and objects lit by a golden sunlight (see Plates 3, 4, 5 and 6). The soundtrack lets us hear voices, a trumpet and a saxophone rehearsing, some laughter. We understand that a festive celebration is about to take place, and the initial titles have explained that this is "New Orleans", "Three months after" (the omission of "Katrina" implies that the event is so terribly seminal that is does not even need to be named. It is not represented directly on screen either, until the flashback sequence in the final episode of Season 1).

${ }^{4}$ New Harvard Dictionary of Music, Cambridge, MA, Harvard University Press, 1986, p. 646. 

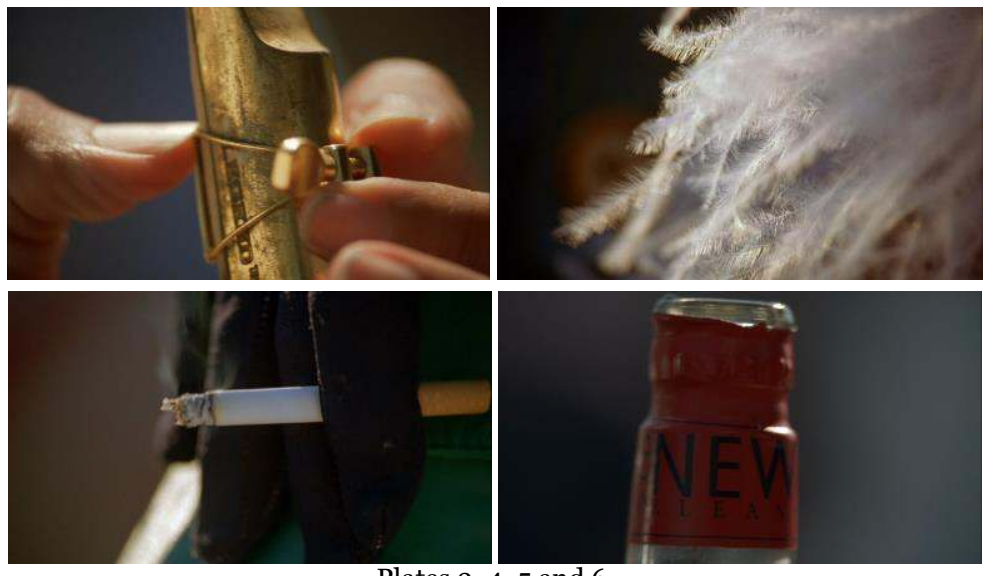

Plates 3, 4, 5 and 6.

The next shots take some distance from the scene and let us see some children dancing, a man clapping hands, and soldiers and policemen overseeing the scene (see Plates 7, 8 and 9), until all these pieces fit together to depict the first Second Line parade 5 getting ready to start after Katrina.
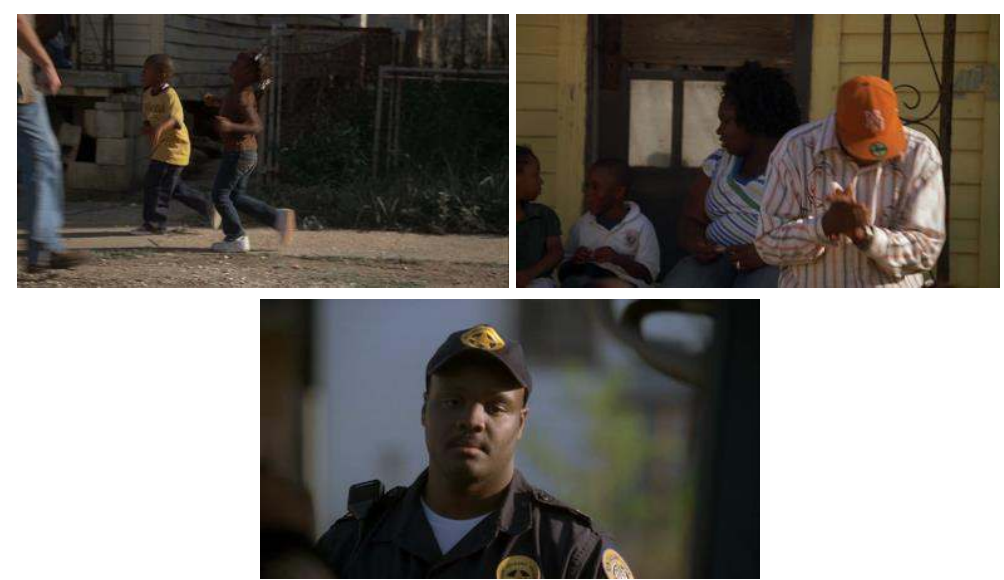

Plates 7,8 and 9 .

5 The expression "Second Line » originally referred to funeral parades in New Orleans, where the brass band would play upbeat music when returning from the ceremony. It has then become associated with musical parades and with New Orleans traditional music in general. For more information see http://www.neworleansdrumming.com/?id=8 Consulted August 13, 2013. 
The final part of the sequence depicts one of the main characters, Antoine Batiste, a trombone player struggling to get some work, hurrying to join the band (real-life Rebirth Brass Band) at the front of the second line and, after exchanging a few jokes, "playing for that money" with them (as Antoine Batiste concludes at the end of their exchange, using a common New Orleans expression for street performers, "Play for that money, boys, play for that fucking money!"). The final shot is a circular camera movement around the line of players while the musicians sing the chorus "I feel like funking it up", enhancing the cohesion and dynamics of the group, as if materializing the purpose of the bits and pieces we had witnessed before.
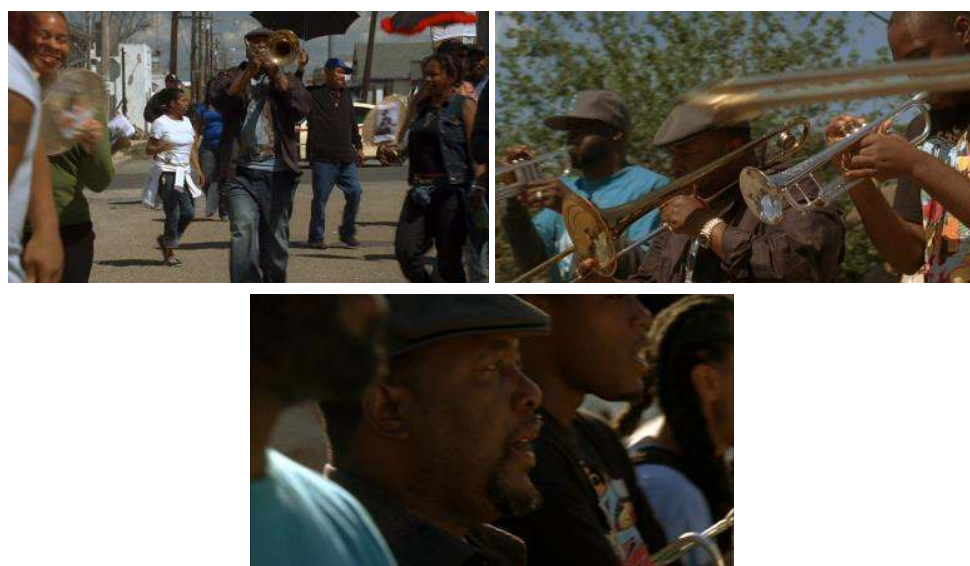

Plates 10, 11 and 12.

From details to the whole, the sequence focuses on the moment when the individual character (Batiste) joins the group (the Rebirth Brass Band), and they adopt the same rhythm (see Plates 10, 11 and 12). It is also the moment when the series actually begins, with the opening credits.

The musical quality of the series is logically linked to the precision of the soundtrack and sound design, and the attention to sound definition and sound textures echoes the sophistication of the musical score. Beside the actual musical performances, the series

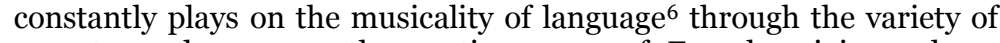
accents or languages, the exotic names of French origin such as Robinette or Desautel, and through the high definition of sounds and noises as well. In Season 1, the noise of helicopters patrolling over the city regularly reminds us that Katrina is still a very recent wound. In

${ }^{6}$ The Wire and Generation Kill already did that, although in a slightly different way. 
Season 2, the chime of the streetcar symbolizes another step in the recovery of the identity of the city. This is what Celia Wren calls the "brilliantly textured sound design", an "auditory layering" which "engulfs you in the invented reality 7 ".

But, as the opening credits already showed, the visuals are not secondary in Treme; the cinematography and camerawork are in close symbiosis with the sound design and sustain the interweaving pattern of jazz music throughout the series. The pre-credit sequence of Season 1 , episode 4 is not strictly speaking about a regular musical performance, yet it illustrates the way music is literally embedded in the series. Character Antoine Batiste finds himself in the emergency room of the local hospital. The scene in the waiting area manages to illustrate the dysfunctional public hospital service, the poor state of health of the people of New Orleans, as well as the ability to cope through music, and how music turns a crowd into a community. Aurally, the sequence plays on the texture and musicality of voices: we can hear different languages or accents - a Latino couple speaking Spanish, the nurse calling a patient called "Bocage", or referring to a doctor called "Weisserman"; the impersonal, stressful announcements on the loudspeaker also contrast with the moment when Batiste switches from language to song, adapting the lyrics of jazz standard "St James Infirmary" to this specific situation. All these seem to cohere into a more harmonious unit once Batiste starts singing: his melody is accompanied by a man with a breathing mask using a trashcan as a drum, but also by the laughter, singing along and shouts of approval of many other patients who join in.

Visually, the relationship between Batiste's body and its surroundings also evolves: we see him at first as only one element of the frame until the final shot, which brings the audience in, because of the combined movements of pull in / zoom out (which reminds us of the opening credits) and the slightly low angle shot, together with the way he smiles and looks almost directly at the camera (see Plates 13, 14,15 and 16).
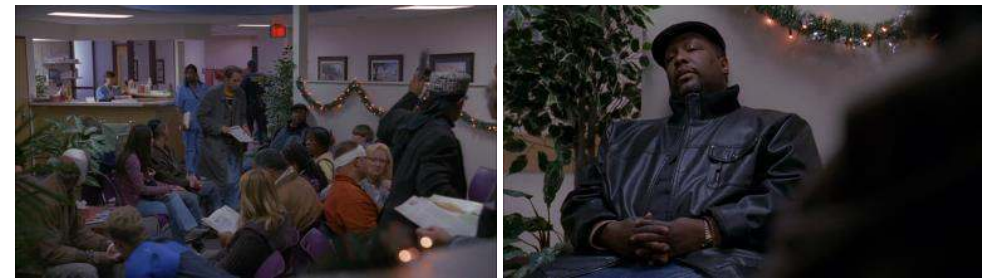

7 Celia Wren, "Urban studies; David Simon's Treme", Commonweal, Vol. 137, No. 8, April 23, 2010, p. 21. 

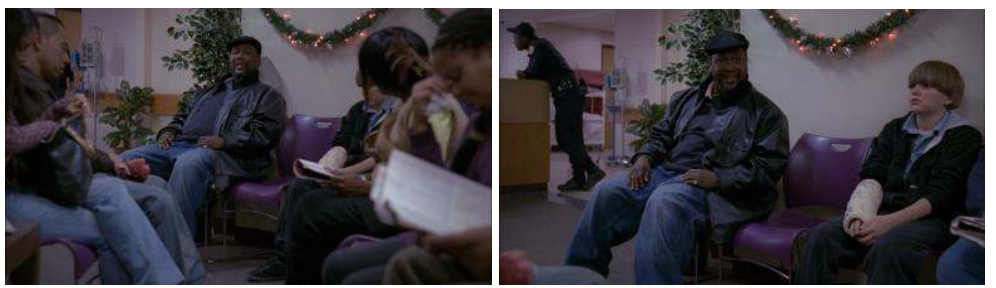

Plates 13, 14, 15 and 16.

The character is thus somewhat magnified, and the audience is literally drawn by the camera movement into the fictional world at the moment when music creates a community out of a random collection of hurting individuals, and thus manages, albeit temporarily, to transcend pain and trouble. Culture appears as the only way to cope with the tragedy and the feeling, above all, of absolute transience that presides over human existence, especially for the man in the street, in a place like New Orleans.

Forgetting the horror by creating beauty, transcending trouble through harmony and art, this is also what Treme is about, just as the opening credits use photographs that transcend the horror of the flood by making the mold and waterline beautiful onscreen. In the two seasons broadcast so far, the final episode features a montage sequence as a sort of wrap up for the season (close to what each season of The Wire did). In Season 2, the song featured as score is Louis Armstrong's "Wrap Your Trouble in Dreams", a sentence which was also used as the tagline of the season. According to executive producer Nina Noble ${ }^{8}$, this was what the season tried to convey: "the sense of people putting their troubles aside and a little bit of denial of what was going out, and coming out and being part of a community despite whatever troubles they had".

We could go on studying the many ways in which Treme could be called musical and echoing in terms of construction or rhythm: the call and response pattern common to blues and Mardi Gras Indian chants could for instance find its cinematic equivalent in the way the individual trajectories are edited together to reflect on a common theme, or the motif of syncopation could serve as a paradigm to shed light on the variations of rhythm and the refusal of acceleration or simplification in the series, or on the great sense of timing in the precredits sequences. But my main point in this article will be the participatory dimension of these aesthetic choices: the audience is required to "join in" as in the teaser I just mentioned. Not only to sing along, but to fill in the gaps in the narrative. As in The Wire and Generation Kill, a lot remains unexplained at first and is left for the

\footnotetext{
${ }^{8}$ See her episode commentary, Season 2 episode 11.
} 
audience to make out for themselves. Spectators are encouraged, by hints or clues, based on systems of echoes and repetitions, to complete the narrative and appropriate it, just as the audience of a second-line is an active participant of the musical performance. If we are not familiar with the levee system, with Mardi Gras Indians, or the musicians that we see perform live, are we left out? Of course the series at first does not resonate in the same way for those who are familiar with New Orleans, its culture and history, and for the others. These faces, places and performances, cultural references that abound could at first be perceived as strange. But gradually, by a system of echoes, repetitions or recurrences, the show makes them familiar. It also offers, through characters that are outsiders, points of entry for the audiences, and like them we are asked to participate and encouraged "to visit". This dimension of the show has led to some criticism that considers Treme as a new form of dubious televised tourism, with its documentary use of real places, real people and real events and their insertion into a fictional frame.

\section{The Reappraisal of Politics through Music}

These objections have notably been voiced in a recent issue of Television and New Media, in which some critics regret for instance what is considered to be the "spectacularization" or "commodification ${ }^{10 "}$ of New Orleans' black expressive culture. For some, the emphasis on jazz and heritage music "render[s] the city's history of racial conflict and injustice invisible or subordinate to new narratives of cross-racial unity among Katrina survivors ${ }^{11}$ ". Viewers become "televisual tourists" that are lulled into believing they have access to the "real" New Orleans ${ }^{12}$.

But if music is the end and not the means in Treme, it does not mean that all social, political, or racial issues are subsumed in a fantasy of harmony and sweet brotherhood. The music itself is political, in the show, and stands against a common consideration of music as mere entertainment. The musical score of Treme thus allows the audience a mediated access to the ideological and political message of the series. Instead of choosing a single, prettified approach to culture and life in New Orleans, the series inscribes dualities and tensions within the script, the characters and the culture (or cultures) they uphold.

\footnotetext{
9 On this, see Joy V. Fuqua, “In New Orleans, We Might Say It Like This”, Television and New Media, Vol. 13, No. 3, May 2012, p. 235-242.

${ }^{10}$ Hel Morgan Parmett, "Space, Place, and New Orleans on Television: From Frank's Place to Treme", Television and New Media, Vol. 13, No. 3, May 2012, p. 193-212.

${ }^{11}$ Lynnell L. Thomas, "People Want to See What Happened: Treme, Televisual Tourism, and the Racial Remapping of Post-Katrina New Orleans", Television and New Media, Vol. 13, No. 3, May 2012, p. 216 [p. 213-224].
}

12 Ibid. 
Tensions between traditional jazz and modern jazz for instance are embodied in the character of Delmond Lambreaux, the son of a Mardi Gras Indian chief who is a modern jazz musician who has apparently broken away from tradition (and from what could be seen as a commodified version of jazz in New Orleans) and moved to New York in Season 1, and who then tries to combine tradition and modernity in Season 2. Instead of pretending to be the absolute representation of "the real" New Orleans, the show repeatedly questions this idea of authenticity by applying it to the culture and the music, as another article in Television and New Media showed, which focused on several occasions in which the show "questions how race and class segregation and the outsider tourist consumption of New Orleans music have affected the production and perceptions of jazz ${ }^{13}$ ". According to Courtney George, Treme "meditates on the overall nature of authenticity as both pluralistic and subjective ${ }^{14 "}$.

In terms of race, the choice of a title, first, links the culture to a specific history. Treme is the name of a historic neighborhood, historically the main neighborhood of the free people of color, which is still a very mixed area. It contains Congo Square, where slaves gathered on Sundays to dance or where open air markets allowed colored populations to meet and play music, and which is considered as the birthplace of African American music, and notably jazz. The colonial history of America's oldest surviving black community and neighborhood is thus present in the very concept of the show. Racial tension is also represented for instance indirectly through the character of DJ Davis, who aspires to embody some of the features of African American culture despite his white, privileged background. As anthropologist John Jackson writes, Treme's focus on jazz and music in general is not a way to avoid the issue of race or negate racial tensions. It chooses, deliberately, a "kind of meditation on racial difference and on the various ways in which blackness and whiteness share history in the South", and in New Orleans in particular. Jackson continues:

If jazz music can tell us something about how class conflicts and racial reasoning play themselves out, Treme seems to also imply that such music isn't reducible to these social and political issues [...]. In that sense, Treme's hyper-realism seems almost utopian, as though it imagines that the objective artistry of musicians and their music, if taken seriously, could keep the waters from rising next time around ${ }^{15}$.

13 Courtney George, "Keeping It 'Reals': Narratives of New Orleans Jazz History as Represented in HBO's Treme", Television and New Media, Vol. 13, No. 3, May 2012, p. 225 [p. 225-234]

${ }_{14}$ Ibid.

15 John L. Jackson, Jr., "HBO's Utopian Realism: Down in the Treme", Transforming Anthropology. Journal of the Association of Black Anthropologists, Vol. 19, No. 1, p. 20 [p. 17-20]. 
What is at stake here is indeed the way music and culture seem to sometimes transcend tensions and tragedy, which for some is seen as a dubious idealization or at least a dangerous attenuation of racial issues, through the idealization of jazz as mongrel art, as a "gumbo pot" (the New Orleans culinary equivalent of the melting pot), a romanticized myth of the fusion of European and African origins. Just as The Wire has sometimes been criticized for being too dark and unrelenting ${ }^{16}$, Treme would then be judged for presenting a more optimistic, or simplified approach. Treme does glorify a popular, active, living culture that is more than a myth in contemporary New Orleans. I believe that what these criticisms reveal is a sense of discomfort towards the balance between reality and fiction that Treme offers. The series indeed resorts to many aspects of the documentary but also to a great formal stylization and great artistic coherence, using notably great fiction writers (George Pelecanos, Tom Piazza) to give flesh to properly fictional characters within a realistic, highly documented framework. Using a real place, choosing to shoot everything on location, basing the show on a historical trauma, using extensively the "real" culture of New Orleans, leads a part of the audience to expect from Treme what one would expect from a documentary or filmic essay. What prevents Treme from "taking up when the Katrina tour stops ${ }^{17}$ ", from being merely a touristic approach of a pseudo-"real" New Orleans, is the fact that it is fiction, and great fiction, with well-written characters, and a daring, original approach to the association between film and music whose cinematic ancestors could range from Robert Altman to John Cassavetes. It is about New Orleans, a historical period and social issues, but it is also, and mainly, as the creators express, about culture and about beauty. Not art as an elite feature, available to those who have the cultural capital to appreciate it, but about art and culture in a place which has managed to keep these things lively in all social classes, not in a logic of consumption - consuming art produced by others - but in a logic of production and participation. All the characters in Treme produce or uphold culture (in the form of food, education, tradition, or legal issues) in their daily lives, and this is the main feature that links them together.

The participatory and collective dimension of music in the show could also be seen as close to the creative process of the series itself. In a conference, Simon explained that he did not consider the shooting of the opening scene a success ${ }^{18}$. It was highly staged, with a powerful

${ }^{16}$ See for instance John Atlas and Peter Dreier, “Is The Wire Too Cynical?”, Dissent, Vol. 55, No. 3, Summer 2008, p. 79-82.

17 Thomas, p. 216

18 "The Art of Treme", DVD4, Season 2. 
mise en scène, and the shooting did not go well because they had to ask the musicians to stop and do it again, which the latter did not like. Having sensed this, the producers, for the next second line scene, adapted their strategy, decided to have a less scripted approach, and modified their shooting technique to avoid interrupting the flow and to remain open to spontaneous interaction between the musicians, the actors and the extras. The result was a sequence that was maybe less slick, but which allowed more room for spontaneity and surprise. Knowing this about the shooting helps us understand that this particular series relies on variations and improvisations on a given theme or motif, which echoes the balance, in the genesis of the series, between a guiding vision (that of the showrunners) and the individual creativity of a plethora of other authors. Film and TV series are both collaborative forms of creation, but in Treme as in The Wire, the overall alchemy relies on the combination of strongly individual creators. If the templates of the show have been set by creators David Simon and Eric Overmyer, and the overall shooting is overseen by them and two other executive producers (George Pelecanos and Nina Noble), the series also relies heavily on the creativity of individual artists such as fiction and nonfiction writers (Piazza, Pelecanos, Lolis Eric Elie) and musicians (Kermit Ruffins, Dr. John, Donald Harrison, $\mathrm{Jr}$, etc.). The ability to combine these strong, individual creativities into a truly collaborative, communal creative process reminds us necessarily of jazz and the combination between improvisation, individual creativity, and the ability to blend into a coherent, possibly harmonious whole. The result may sometimes be magical, sometimes uneven or flawed, but it remains a unique creative experience, a singular example of television performance.

\section{Bibliography}

Atlas John and Peter Dreier, "Is The Wire Too Cynical?", Dissent, Vol. 55, No. 3, Summer 2008, p. 79-82.

BlumenFeld Larry, "Rhythm and Blue. David Simon's New HBO series Treme Moves to a Crescent City beat”, Billboard, 10 April 2010.

FuQuA Joy V., "In New Orleans, We Might Say It Like This”, Television and New Media, Vol. 13, No. 3, May 2012, p. 235-242.

George Courtney, “Keeping It 'Reals': Narratives of New Orleans Jazz History as Represented in HBO's Treme”, Television and New Media, Vol. 13, No. 3, May 2012, p. 225-234. 
JACKSON, John L. Jr., "HBO's Utopian Realism: Down in the Treme", Transforming Anthropology. Journal of the Association of Black Anthropologists, Vol. 19, No. 1, p. 17-20.

PARMETT, Hel Morgan, "Space, Place, and New Orleans on Television: From Frank's Place to Treme", Television and New Media, Vol. 13, No. 3, May 2012, p. 193-212.

Thomas, Lynnell L., "People Want to See What Happened: Treme, Televisual Tourism, and the Racial Remapping of Post-Katrina New Orleans", Television and New Media, Vol. 13, No. 3, May 2012, p. 213224.

WoODALL, Tim, "Treme: The most musical TV series ever?", The Independent blog, 25 October 2011.

http://blogs.independent.co.uk/2011/10/25/treme-the-most-musicaltv-series-ever/ Consulted December 13, 2012.

Wren, Celia, "Urban studies; David Simon's Treme", Commonweal, Vol. 137, No. 8, 23 April 2010, p. 21.

\section{The author}

Ariane Hudelet is Assistant Professor at Paris Diderot University. She teaches in the English department and specializes in adaptation studies and TV series. She wrote several articles on TV series, notably on opening credit sequences (http://www.graat.fr/tvo1hudelet.pdf); she is also the author of Pride and Prejudice: Jane Austen et Joe Wright (Armand Colin, 2006) and co-author of The Cinematic Jane Austen (with David Monaghan and John Wiltshire, McFarland, 2009). She co-edited two volumes on film adaptation with Shannon Wells-Lassagne (De la page blanche aux salles obscures, PUR, 2011; Screening Text, McFarland, 2013). She co-edited the first volume of TV/Series with Sophie Vasset, "Les Séries télévisées américaines contemporaines: entre la fiction, les faits et le réel" (http://www.univ-lehavre.fr/ulh services/Numero-1-Issue-1juin-2012.html). 